\title{
On Translation of Puns in Sitcoms Based on Functional Equivalence Theory - Taking Yes, Minister as an Example
}

\author{
Liangcheng Wang \\ School of Foreign Languages and Literatures, Lanzhou University, Lanzhou 730000, Gansu, China \\ wanglch21@lzu.edu.cn
}

\begin{abstract}
In situation comedies, pun is one of the most effective means of creating comic effect and takes up a considerable part. However, if incorrectly or improperly translated, it can be almost impossible for puns to get across its audience, even when the audience is somewhat capable of English. The reason is that pun, in essence, is a figure of speech, which requires certain knowledge of English literature and culture. The translation of English movies and TV series has become fairly sophisticated, but studies on the translation of pun are relatively rare. This article will introduce and study pun both in Chinese and English literature by the approach of contrast, and discuss the translation methods of puns from the perspective of functional equivalence theory; and then it will take the Chinese subtitle of the famous situation comedy series Yes, Minister as examples to analyze and study the translation methods and strategies of puns used in situation comedies.
\end{abstract}

Keywords: Pun, Situation comedy, Subtitle, Functional equivalence theory.

\section{Introduction}

\subsection{The Sitcom Yes, Minister}

Yes Minister is a British political satire sitcom written by Antony Jay and Jonathan Lynn. Comprising three seven-episode series, it was first transmitted on BBC2 from 1980 to 1984. Almost all episodes end with a "Yes, Minister" spoken as the answer to a question posed by Minister Jim Hacker. Several episodes were adapted for BBC Radio; the series also spawned a 2010 stage play that led to a new television series on Gold in 2013.

Yes, Minister revealed the shocking bureaucracy and corruption in politics in a comic and satirical way, and it was a huge hit once it had been transmitted. In response to such a smear, Sirs in the House of Commons can't help leaving for home early to enjoy it. The prime minister then, Margaret Thatcher, was a great fan of it and she even starred a play with the actors of Yes, Minister. It was so popular that the China Central Television even introduced some of the series in 1990s.

\subsection{Language Characteristics in Yes, Minister}

Although the mean purpose is to discuss the translation of puns in Yes, Minister, we can not really single out this particular one item for that the translation concerns all parts of the sentences, even the circumstances and the mood of the speaker. First the characteristics of the language will be introduced.

\subsubsection{Informality}

Although the series depicts life in politics, the dialogues happen mostly in private offices and, therefore, are casual and colloquial. Some dialogues contain political terms but most of them are very basic which would not impair but boost the comic effect even if incomprehensible. Informality is an important element of spoken English. As the authentic material of spoken English, many informal words can be found in sitcoms, which fall broadly into two categories: contraction and phrase replacement.

Contraction is a shortened term formed by omitting the middle of a word or words. It is a device often employed to reduce the length of the utterances for effort-saving purpose. For example, "we're" instead of "we are," "I'll" instead of "I will."

In daily conversations, phrases deriving from general words are frequently used to replace the comparatively complex and formal words. They would say "run into" rather than "encounter," "pull off" rather than "succeed," "root for" rather than "support."

\subsubsection{Small Words}

According to Douglas Biber, words can be divided into three classes in correspondence with their functions and their grammatical behaviors: lexical words, functional words, and inserts. Inserts refer to words inserted freely in the text without any integral function in a syntactic structure. Their existence marks intonation, pause, and in situation comedies, suggestion, agreement and hesitation.

Words such as "you know," "see," "I mean," "well" attach additional, stylistic function and sometimes little clear content. Hasselgren call them small words. They break into speech in order to maintain the continuity of discourse with the planning process underway. Better than pause and paraphrasing, the addition of small words is a strategy to make the conversations more fluent as they deal with linguistic uncertainty. 


\subsubsection{Vague Terms}

The application of the vague terms is one of the most important characteristics of conversations. In conversations, many vague terms are applied because the speakers try to avoid the repetition of similar meaning due to the shared contextual background. The most frequent used vague terms include "kind of," "sort of," "or something," "and stuff," etc.

\subsubsection{Slang}

The frequent occurrence of slang is one of the major characteristics of sitcoms. Slang is language (words, phrases and usages) of an informal register that members of particular in-groups prefer over the common vocabulary of a standard language in order to establish group identity. The series contains some slang with British culture and politics, vivid and expressive.

\section{Example 1:}

Sir Desmond: If you spill the beans, you open up a whole can of worms.

How can you let the sleeping dogs lie, if you let the cat out of the bag?

Bring in a new broom and, if you're not careful, you find you've thrown the baby out with the bath water.

If you change horses in the middle of the stream, the next thing you know, you're up the creek without a paddle.

\section{戴斯蒙爵士: 一旦你露了馅, 开弓可没有回头箭。 \\ 要是您不想招来苍蝇, 又怎能去捅马蜂窝? \\ 要想注入新血, 一不小心, 可能就得刮骨疗毒顺带割肉。 临阵突然换了将, 四面楚歌也怨不得谁。}

\subsubsection{Vulgar Words}

Vulgar is a derivative from a Latin word "vulgus" meaning "folk." Vulgar words can be found often in colloquial, or rather, in unrefined and low speech. Nevertheless that doesn't mean that people as high as cabinet secretaries can exclude themselves from speaking them. Vulgar words are ways to vividly to express mood and immediate reaction. "Bloody" is one vulgar word distinctive of British people and often said in the series to express anger.

\section{Example 2:}

Sir Humphrey: Have you read this?

Hacker: Yes! Yes! Yes! I have read it! I have read it. You have read it. He has read it. We have all bloody read it!

\section{汉弗莱爵士：你看了吗？}

哈克: 看了! 看了! 看了! 我看过了! 我看过了, 你看过 了, 他也看过了。我们都他妈看过了!

\subsubsection{Long and Complicated Sentences}

Furthermore, in order to show "bureaucracy," some of the sentences last more than one minute, which is the most distinctive feather of Yes, Minister. Such sentences are usually spoken by the civil servants to confuse Hacker, the Minister for the fictional Ministry of Administrative Affairs, on purpose. However, the translation of such long, difficult, and term-racked sentence is not the point and the subtitle does not need to be comprehensible because the lines were designed to be long for the length's sake.

Example 3:

Sir Humphrey: If there had been investigations, which there haven't, or not necessarily, or I'm not at liberty to say whether there have, there would have been a project team which, had it existed, on which I cannot comment, which would now have disbanded, if had it existed, and the members returned to their original departments, if indeed there had been any such members.

汉弗莱爵士: 即使有过调查, 其实要么没有, 要么没必要, 要么我无权透露, 那就必然有过一个研究小组, 其存在过 与否我无可奉告, 即便存在过, 也已经解散了, 成员已经 各自回到曾经的部门, 如果真的存在过这些成员的话。

\subsection{About the Translator}

With the wide spread of internet in China, Chinese people realized that there is a plethora of excellent TV series and movies in country like US, UK, Japan and Korea. However, as the official importer of such works, China Central Television has been considerably inactive is this field for many reasons, which sparked off the inception of so-called Subtitle Groups (字幕组) in 2001. And the Rag Bear (破烂熊字幕组), founded in 2002, was one of the first and most reputable organizations, famous for its translation of British TV series.

What makes the Rag Bear so distinguished is that anyone with a good command of English can see that they paid such close attention to the translation that the outcomes were so natural and of the best quality. The members of this group were responsible, dedicated, and even made introduction pamphlets for some TV series.

Sadly, the quality of its translation dwindled after 2010 and then the Rag Bear eventually disbanded.

\subsection{Characteristics of the Subtitle}

\subsubsection{Authenticity}

Faithful translation is good enough, but authentic translation may be better, on the premise that the altered translation doesn't change the meaning and that it's not rigid texts such as government papers which we would better stick to the original form.

Dialogues in sitcoms are colloquial and, if translated plainly, can be fairly boring. If the translation is authentic Chinese, it can make the reading while watching process more relaxing 
and natural, and for long sentences, it would still make sense if the audience does not have time to read every word.

Example 4:

Hacker: Well, I would say no, I've known this sort of thing happen before.

哈克: 算了, 我听过这种事。

In this example, the translator omitted "well," and didn't translate "I would say no" directly. Instead, the meanings of these two parts were mixed together into “算了." First of all, if the subtitle were “好吧, 我觉得不了, 我知道这种事以 前发生过,” it would be too long to read. For viewers without language capacity, the image would be missed if too much attention were paid to the subtitle. Furthermore, this is not what we would say in a casual situation. "Well" here shows that Hacker is resigned, he gives up, and the middle part explicitly expresses the idea. “算了” can express his downcast and hopeless emotion and the fact he gives up in a very short and authentic form. What's more, if he heard something, this thing must "have happened." people can not hear about something that never takes place. So in order to express the fact without redundancy and to make it easy to read, it can be translated to “我听过这种事.”

\subsubsection{Flexibility}

The structure of Chinese differentiates itself from that of English in many ways. For example, Chinese express a idea in a positive way, while English natives may say it in a negative tone. In such circumstance, a straight translation may seem awkward, and viewers are likely to concentrate on the subtitle and read carefully to understand what it really means. Thus, it is important to change the expression while translating.

Example 5:

Sir Desmond: This is how we make our profits. Six extra storeys and we are really clean up.

戴斯蒙爵士: 不然怎么赚钱啊, 多造六层才能大翻身。

The direct translation is “这就是我们获得利润的方式, 六 层额外的楼层, 我们才能赚大钱." However, although this sentence is normal in English, this is an awkward expression for Chinese and a little formal. “赚钱” is more common for Chinese, and “不然” instead of “这就是...的方式” is both shorter and better to show his desire for money. "Clean up" is a phrase that means "to make great profits." But two “赚钱” in a sentence is excessive and awkward, so the translator chose another phrase and made it much more vivid for Chinese viewers.

\section{Functional Equivalence Theory}

\subsection{Definition}

The translation theories of American linguist and translation theorist Eugene Nida were among the most influential theories in China since the 1980s. His most notable contribution to translation theory is Functional Equivalence.

The long-term used words throughout history, such as "literal translation," "free translation," and "faithful translation" were discarded by Nida. On the contrary, he advocated two "equivalence" ways as the basic directions and guidelines of translation: dynamic equivalence and formal equivalence. Later he replaced "dynamic" in the name with "functional."

Formal equivalence strives to keep the form and content contained in the original message. The so-called formal equivalence means that the message in the target language should be in accordance with the different parts in the original language. It intends to achieve equivalence between original text and translation text, and reflect the linguistic features as much as possible, such as vocabulary, grammar, syntax and structure of the original language which have great impact on the accuracy and correctness.

However, it is Nida's belief that translating is communicating, and this process depends on what is received by persons hearing or reading a translation. Judging the validity of a translation can not stop with a comparison of corresponding lexical meanings, grammatical classes, and rhetorical devices. What is important is the extent to which receptors correctly understand and appreciate the translated text.

In short, formal equivalence focuses attention on the message itself, in both form and content, while dynamic equivalence is seeking the closest natural equivalence to the source language message.

As Nida made clear in his book Language Culture and Translating, a minimal, realistic definition of functional equivalence could be stated as "The readers of a translated text should be able to comprehend it to the point that they can conceive of how original readers of the text must have understood and appreciated it." And a maximal ideal definition could be stated as "The readers of a translated text should be able to understand and appreciate it in essentially the same manner as the original readers did." Therefore, the translator's task is to perceive the global meaning of the source text and to reproduce it in the target text [1].

\subsection{Principles for Producing Functional Equivalence}

First, if a close, formal translation is likely to result in a misunderstanding of the designative meaning, certain changes must be introduced into the text of the translations or the literal translation may be retained and a footnote explaining the likely misunderstanding must be added.

Second, if a close, formal translation makes no sense, certain changes may be introduced into the text unless the text is purposely obscure.

Third, if a close formal translation is so semantically and 
syntactically difficult that the average person for whom the translation is being made is very likely to give up trying to understand it, certain changes are warranted, although it may be useful to indicate the nature of such changes in an introduction or in footnotes.

Fourth, if a close, formal translation is likely to result in serious misunderstanding of the associative meanings of the source text or in a significant loss in a proper appreciation for the stylistic values of the source text, it is important to make such adjustments as are necessary to reflect the associative values of the source text.

Fifth, the manner in which a translation is to be used has a significant influence upon the extent to which adjustments are to be made.

Sixth, the fact that a source text must be translated in such a way as to occur with accompanying codes usually requires a number of adjustments on all levels: phonology, lexicon, syntax, and discourse.

\section{Translation of Puns under the Guidance of the Theory}

\subsection{Pun in Chinese and English}

The English “pun” and the Chinese “双关” have long been considered as absolutely equivalent rhetorical devices, but in fact they are not the same in every department [2].

\subsubsection{In Chinese}

The word “双关” in Chinese is always expressed in a full phrase “一语双关," which determines the boundary of Chinese “双关” that the device is confined to one word or phrase, while English pun can associate two or more. According to Chen Wangdao, a Chinese linguist and translator, Chinese “双关” is a rhetorical device that uses one word that concerns two different things. And as was stated by Zhang Gong, between the two meanings concerned, it is the one underneath the surface that is more important.

Chinese “双关” consists of two categories. “谐音双关” and “语义双关.” The first one “谐音双关” means that on the surface the word or phrase means a thing, however the real intention is another thing that sounds the same or almost the same. “语义双关” means that one word or phrase, with proper background or foreshadowing, can have two meanings at the same time.

\subsubsection{In English}

Unlike Chinese, English pun can use two or even more words. It can be generally divided into three categories: paronomasia, syllepsis, and antanaclasis [3]; or five if strictly: with asteismus and extended.
Paronomasia is a form of word play for an intended humorous or rhetorical effect. It exploits the meaning of the word or phrase that sounds the same or almost the same as the word or phrase that is used in a text. It is a match for Chinese “谐音双 关."

In rhetoric, syllepsis is a figure of speech in which a single phrase or word joins different parts of a sentence, which means that the phrase can be interpreted differently, provided the context. It is basically the same with Chinese “语义双关."

It should be noted that in the two devices above, the word in question appears once and once only.

The word antanaclasis originates from a Greek word meaning "reflection." It is the literary trope in which a single word or phrases is repeated, but in two different senses. It is the same as the syllepsis to the extent that the word has two meanings or can be interpreted differently. But antanaclasis prescribes that the word in play appears twice in two contexts and the word in each context can only be interpreted in one sense. As Wang Zuoliang and Ding Wangdao's Introduction to English Stylistics stated, pun is a rhetorical device that express different meanings explicitly by repeating one word. By a looser definition, the second word or phrase doesn't need to be the same as the first, but just sounds like it.

Above are the three general categories of English pun, the first two of which are basically in correspondence with Chinese “双关," while the third one can not fall into the purview of Chinese “双关.” The Chinese rhetorical device that fits the definition of antanaclasis is “换义.” However, in realistic usage, antanaclasis is the one found most frequent. Therefore, it would be impossible, to a large degree, to translate English pun into Chinese “双关” strictly in accordance with their categories.

Asteismus, or ambiguity, often translated as “歧解双关,” is the combination of syllepsis and paronomasia in its form. The word or phrase can be understood in multiple ways, while the difference is that it is not the addresser's intention to make a pun, but objectively it does due to the ambiguity or multiple meanings of the word or phrase.

An extended pun takes advantage of some linguistic phenomena, such as word formation and pronunciation, with certain extent of derivation, to achieve the effect of humor, most found in brain twisters. For instance, "what is the worst kind of fish?" - "selfish."

\subsection{Pun in Yes, Minister}

Pun is a main tool for making comic effect and almost no episode of the series would end without many hilarious puns. The puns in the series are always closely connected to the story and there are several lines of preparation before the advent of the pun. 


\subsubsection{For Sarcasm}

Rhetorical devices have long been utilized to express emotions, and puns always make the emotion much more drastic. Sometimes due to the pun, sarcasm sounds euphemistic, but it is the euphemism that makes it even more sarcastic. To achieve sarcasm, people usually try to single out a word from others' speeches and on purpose use it or understand it in another way, expressing demeaning or derogatory meanings. When a pun is done by such approach, it is an asteismus.

\section{Example 6:}

Ecological Activist: There's nothing special about man, Mr. Hacker. We are not above nature. We are all a part of it. Men are animals too, you know.

Hacker: Emm... I know that. I've just come from the House of Commons.

生态活动家: 人类没有特权, 哈克先生。我们不凌驾于自 然之上, 我们属于自然。您知道, 人也是兽类。

哈克: 我知道, 我刚去过下院。

Or sometimes, people take advantage of certain circumstance and make a pun of it. It seems that the person is talking about the fact but the real intention is to make fun through another meaning. In such cases, the pun may be syllepsis or paronomasia.

\section{Example 7:}

Sir Humphrey: Yes, my minister is concerned that the government will have egg all over its face. Scotch egg, presumably.

汉弗莱爵士: 是啊, 大臣担心政府脸上会被丢鸡蛋了, 大 概是苏格兰鸡蛋了。

In the example above, the government will be humiliated in Scotland, and a vivid phrase "have egg all over its face" is used to describe the situation, which would be in Scotland. "Scotch egg" is a specialty food of Scotland so Sir Humphrey here took advantage of it and made a pun.

\subsubsection{For Pure Fun}

Sometimes the pun is purely for comic effect or to build characters. Under this condition, the puns are, for the most part, taken out of the circumstances and are connected only with specific words or phrases.

Example 8:

Hacker: We need some female mandarins.

Bernard: Sort of satsumas, minister.

哈克: 我们需要一批女官 (又意甜橙)。

伯纳: 那是无籽芦柑, 大臣。
The pun in the example above is simply a word play exploiting the two meanings of "mandarin," and connecting it with the adjective "female." This is purely for fun and is not attacking anyone or containing any implicit intention.

\subsection{Translation of Puns in Yes, Minister}

Subtitle translation is a special field of translation, known as audiovisual translation. Many scholars treat it as an independent activity distinct from interpreting and translation. Compared with other forms of literature, there are several points to pay attention to [4].

First of all, different from written texts, dialogues of drama are to be read and acted on stage and have to represent carefully the distinctions between written and oral discourse. There is nothing quite so boring as having to listen to a discourse prepared in written style. As a result, the manner of translation of subtitle need to be adjusted accordingly. Not only must the length of utterances be adjusted, but the sounds of the translated text must correspond with the facial movements of the picture track, especially insofar as lip movements are concerned.

Next, equivalent puns in Chinese cannot be easily found while translating English puns. It is more common that translation has to be done in another way. For instance, we can use Chinese words to form antanaclasis or extended puns, which are not technically Chinese “双关,” or render the source text with another rhetorical device. Most frequently, a really equivalent is impossible, and this is when the literal translation should be retained and footnotes added.

Furthermore, the correct understanding and expression of context is the core in the translation of pun. Context is the preparation for pun as well as the buffer for translators to make it easier for the audience to understand the translation. To translate pun better, it's the key to grasp the context and present it properly in target language.

Moreover, the purpose of subtitle is to be of service. The aim is that people from different levels, different educational background, and different culture background can all understand the subtitle well. One of the problems is that the puns are sometimes culture-specific, and in consequence it may be difficult for Chinese audience to understand them. Therefore, translators need to consider whether or not to retain the elements of foreign culture.

Last but not least, it should be noted that subtitles shall not be long or it will be a burden for the audience. Translator can omit something unimportant when the translation is already too long, as well as add parts to help the audience understand if a literal translation is insufficient.

\subsubsection{Lexical Level}

In this part, the puns on the lexical level will be discussed. The characteristics of such puns is that they are often taken out of the contexts and can be understood even singled out. The 
translation of such focuses on the words instead of sentences. Yet the translation of the whole sentences need to cooperate the translation of the pun.

Example 9:

Hacker: What do they all want?

Bernard: They are all worried about machinery.

Hacker: Machinery?

Bernard: Yes, for inflation, deflation and reflation.

Hacker: What do they think I am? A minister of the Crown or a bicycle pump.

\section{哈克：他们来想要什么?}

伯纳：他们都担心机器设备的事。

哈克: 机器?

伯纳: 是的, 担心会通胀、紧缩, 以及再通胀。

哈克: 他们当我是什么? 一个内阁大臣, 还是自行车打气 筒。

In example 9, "inflation," "deflation" and "reflation" are the word in question. In English, they are all economical terms and also connected with size change through air. Their literal translations, in the sense of economical terms, can easily arouse the second meaning. Thus, the literal translation is retained.

\section{Example 10:}

Hacker: What will happen to him?

Sir Humphrey: Well, I gather he was drunk as a lord, so after a discreet interval, they'll probably make him one.

\section{哈克: 要把他怎么样呢?}

汉弗莱爵士: 这个嘛, 既然他醉得跟个爵爷一样, 大概要 冷藏一阵, 然后封个爵吧。

In British politics, there are House of Commons, where the policies are passed, and the House of Lords which doesn't have much power. It is a curtain, as far as politics is concerned. In this example, Home Secretary was found driving after drinking, so he will be eased out of politics. The problem of this example is that "drunk as a lord" is usually translated as “酩酊大醉” due to the cultural difference. However, the translator managed to avoid the feeling of discordance by employing “爵爷” which can be associated with “drunk.”

\section{Example 11:}

Sir Humphrey: I'm merely a civil servant. I simply do as I am instructed by my master.

Hacker: What happens if the minister is a woman. What do you call her?

Sir Humphrey: I didn't quite like to refer her as my mistress.

汉弗莱爵士：我只是个公务员，无非是遵照主子的指示。 哈克: 如果部长是个女人, 你怎么称呼她?

\section{汉弗莱爵士：我不太愿意称她为我的“主妇”。}

In the example above, the female form of master, mistress, has a completely different meaning. The literal translations of these two words - “主人” and “情妇” - hardly bear any resemblance. To overcome this difficulty, the translator adopted what people in ancient China call their employer “主子” - and chose to utilize another meaning of "mistress" “主妇” - in which way, although the original meaning was altered, the effect that audience receives remains the same. Functional equivalence was achieved.

\subsubsection{Syntactical Level}

In this section, the translation of puns is analyzed on the level of syntax, which cannot be understood properly if not adjusted according to the sentence. Its translation attaches great importance to its accordance with the sentence, the paragraph, or even the context.

Example 12:

Sir Humphrey: You could say you don't know.

Hacker: You suggest I should lie?

Sir Humphrey: Not you, minister, no.

Hacker: Well, who should lie?

Sir Humphrey: Sleeping dogs, minister.

汉弗莱爵士：说您不知道。

哈克: 你说我不能捅?

汉弗莱爵士：大臣，不是说您。

哈克: 那谁不能捅。

汉弗莱爵士：马蜂窝不能捅，大臣。

Hacker knows something evil, but bureaucracy forbids its disclosure. "Let the sleeping dogs lie" is a phrase that means one should not look for trouble, and is the suggestion given by Sir Humphrey. Here the translator used a Chinese saying “不 要捅马蜂窝” to match it. The challenge here is that in the original text, the phrase is divided into two parts, so must the translation. What makes it more brilliant is that Sir Humphrey suggests he should lie and say he does not know, and the word that matches "lie" in the Chinese saying, “捅," also has the meaning of making something ulterior public which is exactly what Hacker wants to do.

Example 13:

Hacker: [reading a newspaper] It's not the FT to print something like this unless there's something behind it. Is there something behind it, Humphrey?

Bernard: [trying to turn the page] I think sports news is behind it.

哈克: 金融时报不太可能空穴来风, 除非背后另有文章。 幕后有文章吗，汉弗莱?

伯纳: 我想后面是体育新闻。 
“Something” is usually translated as “什么东西," but if the translator did so, the pun would be a stretch. On newspapers must be articles, and “另有文章” is a perfect match for "something behind it." The combination provides immaculate preparation for the advent of the pun.

\section{Example 14:}

There will soon be a cabinet reshuffle, and Hacker worries that he might be demoted. Meanwhile, he has to decide whether or not to attend a foreign meeting.

Hacker: Well, I would say no. I've known this sort of thing happen before. One day you are out of your office, the next day you are out of the office.

哈克: 算了, 我听过这种事。今天你不在其位, 明天你就 不在位了。

“不在其位, 不谋其政” is a sentence from Analects of Confucius, the “在其位” of which means “in the post." And “在位” means “in power.” In British and US politics, there is a phrase to describe the action of competing for the leadership: run for the office. Thus, there are derivatives such as "in the office" and "out of the office," and the latter means "coming out of power." The literal translation “今天你不在你的办公 室, 明天你就失业了” eliminates the pun of the original text. The translator here adopted these two Chinese phrases pertaining to politics and cleverly formed an English-style Chinese pun.

\subsubsection{Stylistic Level}

Apart from delivering the effect of puns, another perspective the translators have to pay attention to is the style of the original texts. Despite the difficulty, the translation should possess as much stylistic resemblance as possible.

\section{Example 15:}

Hacker and Sir Humphrey are on an official foreign trip.

Hacker: What are you doing here?

Sir Humphrey: Purely my sense of "duty-free."

Hacker: Duty-free?

Sir Humphrey: Er... Duty, free from any personal consideration.

\section{哈克：你来干什么?}

汉弗莱爵士：完全出于“免税”的考虑。

哈克: “免税”?

汉弗莱爵士：免除私人考虑，纯为纳税人着想。

The real reason for Sir Humphrey to be on this foreign trip that he wanted to shop without having to pay the import tax slipped his tongue and he cleverly divided "duty-free" into two parts to defend himself. For this example, it is extremely difficult to retain the pun, let alone preserving the style. To overcome this obstacle, the translator also separated “免税,” and, with wit, managed to produce a reasonable save for Sir Humphrey in the same style, different though the excuse is from the original.

Example 16:

Sir Humphrey: It takes two to quango, minister.

汉弗莱爵士: 公营机构要两个人才能运转, 大臣。

This is a special paronomasia that changes a word in a proverb so that people can still understand the proverb yet combined with the meaning of the changed word. Quango stands for quasi non-government organization, and its pronunciation rhymes with tango, which is a part of an English proverb: it takes two to tango. It is often translated as “一个巴掌拍不 响.” If we leave the translation just like this, we can achieve stylistic equivalence, proverb to proverb. However, the translator decided to translate it literally, and then change the word just like the original text, which is another form of stylistic equivalence. Perhaps the translator assumed that Chinese audience could be expected to be familiar with these British cultural factors [5]. From my perspective, the second approach bears certain risk that not all viewers can grasp the underlying pun, and probably the translation doesn't make any sense to some viewer, although I have to admit that the first approach eliminates the pun completely. That's where a footnote is necessary. We can adopt the second translation and, in the meantime, add a footnote explaining the pun and the English proverb.

\section{Conclusion}

In literary translation, sometimes a perfect translation is nearly impossible, and pun is a particularly tricky field. Due to the disparity between linguistic cultures, pronunciations, vocabularies, and grammars, the effect of pun is often lost during the process of translation, making the translation of pun considerably difficult.

People who advocate untranslatability emphasize on the equivalence of forms. However, if translator only focus on the faithfulness on the lexical and stylistic levels, the effect of pun will wither and disappear. If we retreat to the thinking mode that the pun in the translation doesn't have to be thoroughly identical with that in the original text, the translatability just skyrockets.

Chinese phrases are formed with individual characters, whose pronunciations have little association with adjacent ones. Therefore, it is relatively easy to acquire Chinese phrases with partially same-sounding parts. And we need to introduce the idea that translation is to some extent rewriting, especially in the translation of subtitle.

All in all, equipped with an open mind of translation, by taking full advantage of the properties of Chinese language and the subtitles, adopting flexibly many methods of translation, and adding footnotes if necessary, the pun or the effect produced by it can be effectively preserved. 


\section{References}

[1] E. A. Nida, Language Culture and Translating, Inner Mongolia University Press, Hohhot City, 1998.

[2] Y. Zou, "Subtitle Translation of Puns in English Sitcoms from the Perspective of Speech Act Theory-A Case Study of Mind Your Language," Overseas English, (13), pp. 162-164, 2015.

[3] B. Vickers, In Defence of Rhetoric, The Clarendon Press, Oxford, 1988.

[4] V. V. Sdobnikov, "Translation Studies Today: Old Problems and New Challenges," Russian Journal of Linguistics, 23.2, pp. 295-327, 2019.

[5] P. Zabalbeascoa, "Translating Jokes for Dubbed Television Situation Comedies,". The Translator, 2.2, pp. 235-257, 1996. 